\title{
O Brasil e a cooperação em defesa: a construção de uma identidade regional no Atlântico Sul
}

\author{
Brazil and the cooperation in defense: building a regional \\ identity in the South Atlantic
}

http://dx.doi.org/10.1590/0034-7329201400101

ADRIANA ERTHAL ABDENUR*

DANILO MARCONDES DE SOUZA NETO**

Rev. Bras. Polít. Int. 57 (1): 5-21 [2014]

\section{Introdução}

Nos últimos dez anos, o governo brasileiro tem intensificado os seus esforços de cooperação - inclusive em defesa - com os países no perímetro do Atlântico Sul. Destacando a sua condição de país sul-atlântico, o Brasil busca uma aproximação com Estados da costa ocidental da África, não apenas com parceiros históricos, tais como Angola, Nigéria e África do Sul, mas também com os demais países litorâneos. Na América do Sul, o Brasil também reforça seus acordos de cooperação militar com a Argentina e o Uruguai. Apesar de muitos desses vínculos já existirem há décadas, os esforços atuais expressam maior intensidade e uma articulação crescente entre as políticas externa e de defesa brasileiras. Frente a um cenário em que o Atlântico Sul assume nova importância geopolítica, tanto para os atores da região quanto para os de fora, o Brasil utiliza a cooperação para promover a construção de uma identidade regional que começa a alterar as relações de poder nesse espaço.

A literatura acadêmica indica que a construção de regiōes é frequentemente impulsionada por interesses de poder. Por exemplo, um grau de protagonismo nesse processo de construção regional tende a beneficiar os países que lideram o processo, pois estes geralmente o fazem de forma a avançar suas prioridades estratégicas. Neste artigo, examinamos os esforços do governo brasileiro de articular uma identidade sul-atlântica na última década, levando em conta as prioridades da sua política externa para com a ecologia de atores cada vez mais complexa do Atlântico Sul.

\footnotetext{
* Pontifícia Universidade Católica do Rio de Janeiro (PUC-Rio), Rio de Janeiro, RJ, Brasil (abdenur@puc-rio.br).

** Universidade de Cambridge, Cambridge, Reino Unido (danilomarcondes@gmail.com).
} 
A cooperação em defesa implementada pelo Brasil durante esse período está fortemente vinculada à promoção, no âmbito doméstico, da proteção dos recursos marítimos como uma das novas prioridades estratégicas do País. As descobertas recentes de reservas offshore e as perspectivas de exploração do petróleo pré-sal elevam a preocupação com a segurança desses recursos e rotas, alçando a proteção de tais recursos ao mesmo grau de importância que a Amazônia. Por um lado, o Brasil também procura modernizar e expandir a sua capacidade naval, visando também à difusão de uma "mentalidade marítima" entre a população brasileira. No âmbito internacional, o Brasil propõe a expansão das suas águas jurisdicionais junto à $\mathrm{ONU}$, reforçando também seus laços bilaterais e multilaterais de cooperação centrados no Atlântico Sul.

A construção de um "cinturão de boa vontade 1 " permite que o governo brasileiro promova a criação de uma identidade regional sul-atlântica, na qual o Brasil assegura para si uma posição de destaque. Essa identidade está centrada em preocupações com novas ameaças no Atlântico Sul. Portanto, tal estratégia se baseia não apenas na promoção de interesses comuns aos países desse perímetro, mas também na tentativa de minimizar o envolvimento de atores externos, destacando a responsabilidade dos países da região. Tal afirmação ressalta o enquadramento do Atlântico Sul como zona pacífica e livre de armas nucleares, conforme expressado pela criaçãoo da Zona de Paz e Cooperação do Atlântico Sul (ZOPACAS) em 1986. Contudo, o processo de construção da identidade sul-atlântica enfrenta desafios, como a complexidade das relações entre os países da região e atores externos, que combinam elementos de distanciamento e cooperação (às vezes, dentro de uma única relação bilateral).

A construção de uma identidade regional, longe de ser apenas um conjunto de afirmações retóricas, traz repercussões concretas para o Atlântico Sul. Tais esforços auxiliam na ampliação do espaço no qual o Brasil tem condições de projetar sua influência - mesmo além da fronteira marítima. Por outro lado, tal protagonismo, sujeito a interpretaçóes variadas e narrativas concorrentes, poderia provocar novas tensóes - ou exacerbar disputas preexistentes - dentro da região, pois ele não ocorre em um vácuo de poder. Além da presença de atores de fora da região, existem pontos de instabilidade e fragilidade no Atlântico Sul que demonstram os limites da capacidade brasileira de consolidar um projeto regional.

\section{Considerações teóricas}

Longe de serem "naturalmente" delineadas por barreiras geográficas ou características culturais, as regiōes são imaginários políticos, construídos ao longo do tempo por atores motivados por interesses específicos. Assim como o Estado, a região pode, portanto, ser pensada como comunidade imaginada, com dimensões

1 Discurso do Ministro da Defesa na abertura do II Seminário de Defesa Nacional realizado na Escola Superior de Guerra, Rio de Janeiro, 15 de fevereiro de 2012. 
espaciais (Anderson 1983). A rotulação e reificação da região traz consequências concretas, pois o próprio processo de construção afeta a distribuição de poder. Por exemplo, ao assumirem um papel de protagonismo, certos Estados se tornam, efetivamente, os principais construtores da região (region-builders) - influenciando os padrões de amizade e rivalidade entre os Estados que passam a constituir a região. Neumann (1994) coloca algumas das questôes principais sobre a relação entre a construção regional e as dinâmicas de poder: de quem parte a iniciativa de incluir e excluir? Quais as principais intenções, e quais as consequências? Usamos tais perguntas como ponto de partida para analisarmos a construção de uma identidade sul-atlântica, sublinhando o papel do Brasil como construtor da região.

Trabalhando na tradição da geopolítica crítica, Dodds (2011) analisa as práticas e os discursos utilizados pelas autoridades estatais para a construção de identidades regionais. Segundo o autor, mesmo referências discursivas sobre um território já expressam e constituem estratégias em relação à dita região (Dodds 2011). Práticas e discursos cotidianos são co-constituídos na formação de identidades geopolíticas, refletindo a centralidade de representações veiculadas na mídia, em discursos de autoridades ou em documentos oficiais (Benwell e Dodds 2011). Dodds e Ingimundarson (2012) elaboram sobre a importância da análise da relação entre geografias imaginadas, que funcionam por meio da utilização de recursos discursivos como analogias e metáforas, e as práticas e performances dos Estados, que são expressas por meio das suas políticas externas. Utilizando o conceito de nacionalismo territorial, os autores examinam como certas categorias geográficas são constituídas e apresentadas a audiências domésticas e internacionais, e como essas categorias podem influenciar a adoção de determinadas políticas como, por exemplo, o interesse em pleitear uma expansão da plataforma continental (Dodds e Ingimundarson 2012, 22-23). Defenderemos, na presente análise, que tais práticas e narrativas estão presentes na construção do Atlântico Sul por parte de agentes do Estado brasileiro, principalmente os Ministérios das Relações Exteriores e da Defesa e a Marinha do Brasil, que têm assumido um papel central no posicionamento brasileiro relacionado ao Atlântico Sul.

Na disciplina de Relações Internacionais, contribuições sobre a construção de regiōes têm sido desenvolvidas dentro de: estudos de área, principalmente voltados para o Sudeste Asiático (Acharya 2011) e Ártico (Keskitalo 2004); estudos sobre processos de integração regional (Van Langenhove 2011); e cooperação regional em segurança e defesa (Bellamy 2004; Adler e Barnett 1998). Van Langenhove adota o construtivismo social para analisar processos de construção de regiôes. Segundo o autor, as regiōes são sempre construídas por meio do discurso, sendo a regionificação o processo que permite a emergência destas como fatos institucionalizados (Van Langenhove 2011). Procurando ir além de concepções tradicionais a respeito do que constitui uma região, que enfatizam critérios físicos como proximidade geográfica e critérios culturais, Acharya (2011) desenvolve a ideia de regiōes como construções sociais. O autor enfatiza que a mera existência 
de proximidade geográfica e de interações entre os atores de uma determinada área não são suficientes para a formação de uma região, sendo necessária a presença de uma "ideia de região" (Bellamy 2004; Acharya 2011).

Ao apresentar o seu conceito de region-building, Neumann (1994, 1999) argumenta que a identidade de uma determinada região é constituída por uma série de escolhas feitas a partir de consideraçôes históricas e políticas que dependem dos atores envolvidos, que fazem uso do seu capital político para desenvolver representaçōes que constituem a região (Keskitalo 2004). Dentre as práticas que contribuem para a construção da região podemos mencionar: a seleção da área e formato da região, a articulação de uma dimensão simbólica para a região, o desenvolvimento de instituiçốes voltadas para a governança da região aliado a esforços para reforçar o uso de referências à região (tais como campanhas educacionais), e a veiculação das delimitaçôes de área, dos elementos simbólicos e de governança para um grande público, como, por exemplo, por meio da mídia (Keskitalo 2004). Tendo em mente esses elementos, combinamos pesquisa de arquivo com análise de discurso para identificar momentos e componentes chave na tentativa brasileira de se tornar um region-builder no Atlântico Sul.

\section{Pano de fundo}

O oceano é de importância histórica para o Brasil, que tem a costa mais extensa de todos os países que beiram o Atlântico Sul. Durante o período colonial, o Atlântico serviu não apenas como rota de colonização pelos portugueses, mas também como via de transporte dos navios negreiros que traziam escravos da África. Além disso, foi pelo Atlântico que foram lançadas tentativas de invasão pelos franceses e holandeses nos séculos 16 e 17. Durante a Segunda Guerra Mundial, mais brasileiros morreram no Atlântico - com o torpedeamento de embarcações brasileiras por submarinos alemães - que em qualquer outro teatro de guerra. Durante a Guerra Fria, o Atlântico Sul se tornou parte do jogo de poder bipolar. Após esse período, as preocupaçóes brasileiras com a defesa do território nacional se voltaram mais para a Amazônia e a Região do Prata. Embora o pensamento estratégico dominante incluísse o Atlântico Sul, as relações com a África ainda não eram pensadas como sendo vitais para a construção de uma identidade regional (Saraiva 1996).

Mais recentemente, as questôes de segurança tradicional e não tradicional vêm ganhando peso na visão estratégica brasileira. Notadamente, a importância crescente dada aos recursos marítimos como objeto de defesa nacional transparece nos principais documentos da defesa brasileira contemporânea, inclusive a Política Nacional de Defesa (PND) (2005), a Estratégia Nacional de Defesa (PND) (2008) e o Livro Branco de Defesa Nacional (2012). Tais documentos apresentam o oceano como sendo de importância vital para o País e estabelecem os passos para assegurar a soberania brasileira sobre o seu espaço marítimo. Por exemplo, as hipóteses de 
emprego mencionadas indicam que, além de defender as grandes concentrações demográficas e industriais do País, a Marinha também deve se posicionar na foz e nas bacias fluviais do Amazonas, assim como do Paraguai-Paraná.

Além da defesa do território e dos recursos de interesse nacional, algumas novas questões de natureza transnacional surgem no Atlântico, como tráfico de drogas e de pessoas. Além disso, a pirataria, que até recentemente se restringia ao litoral oriental do continente africano, sobretudo na vizinhança da Somália, passa a ocorrer com mais frequência no Golfo da Guiné. Como a expansão dessa prática vem se aproximando das rotas por onde transitam navios petroleiros, o alastramento da pirataria vem causando consternação nos países que detêm interesses na região. Dessa forma, o Ministério da Defesa do Brasil tem expressado preocupação com a possibilidade de que a pirataria atinja interesses brasileiros na África, ou, até mesmo, que chegue até a costa brasileira².

Além das questões de segurança, tais preocupações ressaltam também a importância econômica do oceano para o Brasil. A população brasileira ainda se concentra nas áreas litorâneas, com 26,6\% dos brasileiros residindo em municípios da zona costeira - o equivalente a 50,7 milhōes de habitantes (IBGE 2011). O espaço marítimo em si também é importante para a economia brasileira, já que cerca de $95 \%$ do comércio internacional do País transita pelo Atlântico, e mais de $90 \%$ do petróleo produzido no Brasil vem de plataformas offshore. Em 2008, a Petrobrás anunciou a descoberta de reservas na camada do pré-sal, que posteriormente verificou-se ser um grande campo petrolífero, estendendo-se ao longo de $800 \mathrm{~km}$ na costa brasileira, do Estado do Espírito Santo ao Estado de Santa Catarina, e englobando as bacias sedimentares do Espírito Santo, de Campos e de Santos. Finalmente, além do petróleo, há outros recursos naturais, desde os estoques de pesca até minerais no solo e subsolo marinhos - cuja extração, impulsionada pela alta dos preços dos commodities, já é alvo de prospecção por países de fora e de dentro da região, inclusive o Brasil.

\section{A estratégia brasileira no Atlântico Sul}

\section{Iniciativas no âmbito doméstico}

Alguns dos principais conceitos da estratégia brasileira no Atlântico Sul estão refletidos nos esforços lançados pela Marinha no âmbito doméstico. Em 2004, o então comandante da Marinha apresentou o conceito de Amazônia Azul em texto de opinião publicado em jornal de grande circulação nacional. Usando o simbolismo da Amazônia, o almirante destacou que a soberania nacional se estende à proteção das riquezas naturais oceânicas - o que Keskitalo (2004) chama

2 Disponível em <http://www.bbc.co.uk/portuguese/celular/noticias/2013/05/130513_pirataria_africa_brasil_ jf_lk.shtml>, acesso em maio de 2013. 
de "articulação de uma dimensão simbólica para a região", disseminada pela mídia. Além de ressaltar a necessidade da conscientização da população brasileira a respeito dos direitos que o Brasil possui sobre o mar, o comandante ressaltou a necessidade da presença do Estado brasileiro na Amazônia Azul, justamente pela natureza porosa das fronteiras marítimas (Carvalho 2004).

Para assegurar tal presença, o Brasil também lançou um projeto de modernização militar, incluindo projetos que estavam paralisados desde a década de 1970, como o desenvolvimento do submarino nuclear. Na década de 2000, com a retomada do crescimento econômico, o Brasil passou a dispor de recursos - e de vontade política - para lançar um projeto concreto de reaparelhamento, refletido no aumento de gastos militares. De acordo com o Sistema de Promoção de Investimentos e Transferência de Tecnologia para Empresas (SIPRI), entre 2001 e 2010, os gastos militares brasileiros cresceram 30\%, com uma média de $2,9 \%$ ao ano; de 2004 a 2010, a média anual de crescimento foi de $6,9 \%$. No entanto, destaca-se que os gastos entre 2001 e 2010 mantiveram-se entre 1,5-1,6\% do PIB (SIPRI 2011, 170). Já em 2009, o SIPRI identificava uma relação entre a descoberta das reservas do pré-sal em 2008 e a intenção do aumento nos gastos com defesa, principalmente em virtude da proximidade da área do pré-sal em relação aos limites da zona econômica exclusiva (SIPRI 2009, 204). Os efeitos tardios da crise econômica internacional na economia brasileira levaram a uma redução nos gastos do governo em 2011, atingindo inclusive o orçamento do Ministério da Defesa, que teve diminuição de $25 \%$ do seu orçamento discricionário, afetando principalmente o reaparelhamento (SIPRI 2012, 154). Tal medida demonstra que o interesse em destinar recursos para a proteção de áreas como a Amazônia Azul precisa ser equilibrado com as vulnerabilidades, ainda existentes, do Brasil em relação às oscilaçôes da economia internacional.

Os esforços para assegurar a presença e soberania brasileiras na Amazônia Azul vêm se concentrando no aumento da capacidade naval, não apenas voltados para a força de dissuasão, mas também para a construção de uma força tática de alto grau de agilidade e capaz de levar os conflitos para o mais longe possível da costa brasileira - essencialmente, uma "marinha de águas azuis". De acordo com o Comandante da Marinha, tais esforços demonstram uma assertividade e um reconhecimento de que os interesses brasileiros vão além da Amazônia Azul: "Eles se estendem a qualquer lugar onde um navio navegue sob nossa bandeira, cuja proteção é dever inalienável do Estado Brasileiro. Essa é a importância estratégica da construção do submarino nuclear." ${ }^{3}$

Para alcançar esse objetivo, o Brasil firmou diversos acordos de cooperação internacional. Em dezembro de 2008, o Brasil - cuja Marinha havia dominado

3 Ver: Comandante da Marinha: "A importância da construção do submarino de propulsão nuclear brasileiro." Disponível em <http://www.mar.mil.br/menu_h/noticias/cm/Aimportanciadaconstrucaodo submarinodepropulsaonuclearbrasileiro/Aimportanciadaconstrucaodosubmarinodepnb.htm>, acesso em maio de 2013. 
o ciclo do combustível nuclear - assinou com a França um acordo de cooperação em defesa que previa, dentre outros elementos, a aquisição de quatro submarinos convencionais Scorpène e um programa visando ao desenvolvimento de um submarino nuclear.

Além da frota de submarinos, o Brasil também vem lançando esforços para fortalecer outras áreas da Marinha. Entre 2005 e 2010, o aeródromo São Paulo passou por um programa de modernização, embora permaneça subutilizado. Além de adquirir embarcações de superfície do Reino Unido, a Marinha vem desenvolvendo o Sistema de Gerenciamento da Amazônia Azul (SisGAAZ), cuja função primária será a vigilância por rádio e satélite da costa e da região do pré-sal. Para diminuir a vulnerabilidade estratégica decorrente da concentração excessiva da frota no Rio de Janeiro, o governo também estuda a criação de uma segunda esquadra, possivelmente baseada na costa do Pará (reforçando, portanto, os vínculos entre as duas Amazônias - Verde e Azul). No entanto, os recursos financeiros e institucionais sendo dedicados ao projeto do submarino nuclear são substanciais, sobretudo quando comparados ao resto da Marinha. Só em 2013, o governo federal destinou R \$ 2,5 bilhōes do Programa de Aceleração do Crescimento (PAC) ao Programa de Desenvolvimento de Submarinos (Prosub) e ao Programa Nuclear da Marinha ${ }^{4}$. A opção por investir pesadamente em um projeto de longo prazo - de acordo com a Marinha, o primeiro submarino nuclear deve ser entregue em 2023 - foi uma decisão estratégica tomada pelo governo brasileiro a fim de reforçar sua capacidade de negação do uso do mar, e que coloca o Brasil dentre os poucos países que detêm essa tecnologia - os demais, com a exceção da Índia, sendo justamente aqueles que têm assentos permanentes no Conselho de Segurança: EUA, França, Grã-Bretanha, Rússia e China.

Tais esforços, relacionados a reequipamento, são acompanhados de iniciativas para promover a "mentalidade marítima", que a Marinha define como "convicção ou crença, individual ou coletiva, da importância do mar para a nação brasileira e o desenvolvimento de hábitos, atitudes, comportamentos ou vontade de agir, no sentido de utilizar, de forma sustentável, as potencialidades do mar" (SECIRM 2012). Para disseminar essa visão, a campanha "Amazônia Azul" produz materiais didáticos e lúdicos, distribuídos em parceria com o Ministério da Educação. O programa também vincula os esforços lançados no Atlântico Sul ao Programa Antártico Brasileiro (PROANTAR), criado em 1982, e ressalta a exploração científica e conservação ambiental conduzidas pelo Brasil nas ilhas do Atlântico e na Antártida.

Em segundo lugar, a campanha Amazônia Azul tenta divulgar e justificar, junto ao público brasileiro, a proposta feita pelo governo de redefinição da sua plataforma continental junto à Convenção da ONU sobre o Direito do Mar, de forma a expandir o espaço marítimo brasileiro em até 900 mil quilômetros quadrados.

4 Disponível em <http://www.defesaaereanaval.com.br/?p=19113>, acesso em maio de 2013. 
A Marinha ressalta que, caso a proposta seja aceita, as águas jurisdicionais brasileiras irão totalizar quase 4,5 milhões de quilômetros quadrados - uma área maior do que a Amazônia Verde 5 . Como parte desses esforços, a campanha também visa a incentivar a pesquisa marinha em biodiversidade e mapeamento dos recursos do solo e subsolo marítimos. A intensificação dos esforços de pesquisa traz uma possível vantagem estratégica, pois permite ao governo manter grupos de pesquisadores em ilhas oceânicas brasileiras. Essa presença no Atlântico Sul poderia também reforçar a proposta brasileira de expansão do território marítimo, dado que, em certos casos, a habitabilidade, que diferencia ilhas de rochedos, torna-se um dos critérios para a aprovação da zona econômica especial (ZEE).

Tal preocupação com a proteção dos recursos naturais também se manifesta nos exercícios navais unilaterais que o Brasil vem realizando, que incluem simulações de ações contra ataques terroristas a plataformas de petróleo na Bacia de Campos ${ }^{6}$. Tais atividades refletem a construção, já evidente no discurso oficial, de ameaças relacionadas aos recursos marítimos. Embora a END afirme que "os ambientes apontados [...] não permitem vislumbrar ameaças militares concretas e definidas, representadas por forças antagônicas de países potencialmente inimigos ou de outros agentes não-estatais" (Marinha do Brasil 2008, 46), os exercícios poderiam ser interpretados como indicativos das hipóteses de emprego sendo consideradas pelo governo brasileiro, com ênfase sobre a proteção da costa brasileira e dos recursos offshore.

\section{Iniciativas internacionais}

Aos esforços domésticos já apresentados, soma-se o programa brasileiro de cooperação em defesa no Atlântico Sul. Durante os anos 1970 e 1980, o Brasil já tinha vínculos militares com a África - inclusive a exportação de equipamentos, desde veículos blindados a aviōes, a diversos países africanos (Dávila 2010; Saraiva 1996). Ao longo da última década, o estreitamento de laços entre o Ministério da Defesa e o Ministério das Relações Exteriores tem permitido a expansão da cooperação em defesa seguindo o desejo de reaparelhamento das Forças Armadas e as prioridades da política externa. Apesar do discurso oficial da cooperação Sul-Sul brasileira enfatizar os laços históricos e culturais com a África Lusófona, na área de defesa os acordos e iniciativas englobam uma geografia mais ampla. Observa-se, notadamente, um esforço sistemático de estabelecer ou aprofundar a cooperação naval com todos os países africanos no litoral atlântico, independentemente do tipo de regime e sendo eles ou não de língua oficial portuguesa.

5 Disponível em <http://www.mar.mil.br/menu_v/ccsm/temas_relevantes/am_azul_mb.htm>, acesso em maio de 2013.

6 Disponível em <http://www.naval.com.br/blog/2011/10/24/exercicio-de-incidente-de-protecao-maritimadurante-operacao-\%E2\%80\%9Ctropicalex\%E2\%80\%9D/\#axzz2P8WHYDA8>, acesso em maio de 2013. 
De fato, tais acordos têm um antecedente não lusófono: em 1991, pouco após a sua independência, a Namíbia solicitou assistência da Marinha do Brasil para constituir a sua força naval (Medeiros 2002). Desde que o primeiro acordo de cooperação naval foi assinado, em 1992, o Brasil tem sido responsável em grande parte pela construção da Marinha da Namíbia. O fornecimento de embarcações é explicado pela Marinha do Brasil como abrindo "perspectivas para a exportação de outros meios navais para diversos países, com emprego de tecnologia nacional e participação de empresas brasileiras, fornecedoras de equipamentos e sistemas navais" ". No caso da Marinha, o treinamento de oficiais e praças do país em português também permite ao Brasil exercer uma influência em um contexto de crescente atuação de outros cooperantes, como a China ${ }^{8}$ (Ministério da Defesa 2013; Senado 2012). Essas experiências vêm servindo de modelo para a cooperação em defesa brasileira ao longo da costa da África, sobretudo a combinação de treinamento e fornecimento de equipamentos.

Os esforços de aproximação atuais ocorrem dentro de um contexto sulatlântico diferente daquele encontrado durante a Guerra Fria. O fim do apartheid permitiu uma aproximação diplomática e militar com a África do Sul (Hurrell 1983; Penna Filho 2003). Hoje a cooperação em defesa entre os dois países inclui também o desenvolvimento do míssil A-Darter e de um sistema de vigilância do Atlântico Sul por satélite oceanográfico ${ }^{9}$. Na área naval, os dois países participam (com a Índia) de exercícios navais trilaterais dentro do âmbito do India-BrazilSouth Africa Maritime (IBSAMAR).

Outros acordos foram assinados com parceiros estratégicos na África, tais como Angola - onde o Brasil tem fortes interesses comerciais e que tem sido mercado para a exportação de armamentos brasileiros. Em 2013, o Ministro da Defesa, juntamente com missão de empresários da indústria de defesa brasileira, realizou visita ao país que incluiu o fechamento de contrato para compra de seis aviōes de combate A-29 Super Tucano da Embraer ${ }^{10}$.

Além de parceiros chave como a África do Sul e Angola, a cooperação em defesa também abrange países menores, incluindo Estados como São Tomé e Príncipe, Guiné Bissau e Camarões. Certos acordos incluem cooperação nas ditas questôes não tradicionais de segurança, tais como o tráfico de drogas e a pirataria. A crise do Mali também é apontada como justificativa para fortalecer tais laços; o Brasil vem ressaltando a proximidade geográfica da crise aos interesses brasileiros na África, até mesmo no Golfo da Guiné, argumentando também que o Brasil e seus parceiros africanos devem se preparar no caso de a instabilidade se espalhar

7 Disponível em <http://www.mar.mil.br/menu_h/noticias/ccsm/PresidentedaNamibiavisitaaEscolaNaval.html>, acesso em maio de 2013.

8 Disponível em <http://www.areamilitar.net/noticias/noticias.aspx?nrnot=1225>, acesso em maio de 2013.

9 Disponível em <http://thebricspost.com/brazil-sa-to-jointly-develop-satellite-for-south-atlantic/\#. UhLH59L2_ZV>, acesso em setembro de 2013.

10 Disponível em <http:/www.portugues.rfi.fr/brasil/20130219-angola-compra-seis-avioes-militares-brasileirosda-embraer>, acesso em maio de 2013. 
para o Atlântico ${ }^{11}$. Além do treinamento de oficiais (programas coordenados pela Agência Brasileira de Cooperação, que é departamento do MRE) e o fornecimento de equipamentos, o Brasil vem auxiliando muitos desses países com seus levantamentos de plataforma continental, tendo em vista a preparação de propostas junto à Convenção das Naçôes Unidas sobre Direito do Mar ${ }^{12}$. Dessa forma, o Brasil dissemina sua abordagem no Atlântico Sul, usando a cooperação em defesa como meio de enfatizar preocupações em comum.

Do lado africano, o interesse em cooperar com o Brasil - dentro e fora do âmbito militar - vem aumentando. E, à medida que o apoio africano ao pleito brasileiro por um assento permanente no Conselho de Segurança constitui um elemento estratégico para a diplomacia brasileira, o Brasil tem tido certo sucesso ao ampliar sua base de apoio. Durante visitas de alto escalão, diversos países africanos vêm expressando seu apoio abertamente ao pleito brasileiro. Para os países da costa ocidental, há também um interesse em comum na área de energia, até pelo fato de o Golfo da Guiné concentrar boa parte do petróleo africano, cogitando-se a possibilidade de descobertas semelhantes ao pré-sal brasileiro ${ }^{13}$. No entanto, longe de ser o único provedor de cooperação, o Brasil concorre, ao longo do Atlântico Sul, com os países do Norte e com outros emergentes, sobretudo a China, cujo interesse pelo petróleo africano tornou-se peça chave da sua estratégia energética e que também possui acordos de assistência militar com países africanos.

A cooperação brasileira em defesa também cresce via plataformas multilaterais. Após as iniciativas lançadas em 2007 por Angola para a revitalização da Zona de Paz e Cooperação do Atlântico Sul (ZOPACAS), o Brasil vem assumindo certo protagonismo no processo. Embora a ZOPACAS tenha originado de uma iniciativa brasileira no final da Guerra Fria, foi durante a última década que o Brasil acumulou capital econômico e político suficiente para dar maior fôlego à iniciativa. O Brasil também se beneficia da prioridade americana em conter a China no Pacífico, mesmo que os EUA não estejam de todo ausentes do Atlântico Sul.

A relação com os países africanos da região permite ao Brasil maior controle do chamado "gargalo do Atlântico", área estratégica de afunilamento do oceano, entre os paralelos $6^{\circ} \mathrm{S}$ e $12^{\circ} \mathrm{N}$, por meio do eixo Natal-Bissau ou Natal-Cabo Verde (Leandro 2011). O discurso brasileiro na ZOPACAS ressalta não apenas os interesses em comum entre os países atlânticos da América do Sul e da África, mas também a necessidade de minimizar a presença de atores externos. Como Miyamoto (1987) já observou, mesmo na sua versão original o discurso oficial da ZOPACAS ressaltava a paz e a cooperação sem abrir mão da possibilidade de ampliação do poder naval dos países-membros.

11 Disponível em: <http://www.africa21digital.com/politica/ver/20032142-ministro-das-relacoes-exterioresdo-camaroes-visita-o-brasil-para-reforcar-cooperacao> Acesso em: maio de 2013.

12 Disponível em: <http://www.mar.mil.br/menu_h/noticias/ccsm/cooperacao_Brasil-Namibia.htm>. Acesso em: maio de 2013.

13 Disponível em: <http://www.presaltafrica.com/> Acesso em: maio de 2013. 
Além da ZOPACAS, o Brasil participa da Comunidade dos Países de Língua Portuguesa (CPLP), cuja maioria dos membros está localizada na região do Atlântico Sul ou próximo. Em março de 2010, a organização lançou o projeto de um atlas dos oceanos da CPLP, e circularam propostas de cooperação entre os paísesmembros para extensão de suas plataformas continentais, com assistência brasileira, seguindo o modelo do Plano de Levantamento da Plataforma Continental Brasileira (LEPLAC). Novas áreas de cooperação incluem programas de pesquisa referentes aos fundos marinhos, tais como o Programa de Prospecção e Exploração de Recursos Minerais da Área Internacional do Atlântico Sul e Equatorial (PROAREA) ${ }^{14}$, pelo qual o Brasil vem pesquisando a Elevação do Rio Grande - uma formação localizada em área internacional - a fim de efetuar o levantamento de minerais ali existentes. Finalmente, há iniciativas para a identificação de áreas estratégicas de interesse comum no âmbito de segurança e vigilância marítima (SECIRM 2010). Durante reunião de ministros do Mar da organização, o Brasil apresentou proposta para promoção da mentalidade marítima no âmbito da CPLP por meio da criação de um "projeto pedagógico para a mobilização de professores, alunos e sociedade civil para a importância dos assuntos do mar como um tema da afirmação da cultura e da identidade marítima da CPLP" nos moldes do Programa Operacional Pesca 2007-2013 (PROMAR) e sob liderança de Portugal (Marinha do Brasil, s.d.). Além disso, em 2013 o Brasil sediou a Operação Felino, uma série de exercícios militares da CPLP que foi realizada no litoral do Espírito Santo, com o objetivo de capacitar as Forças Armadas dos países participantes em áreas tais como operações de paz e missóes humanitárias.

Tais iniciativas brasileiras, tanto em cooperação militar quanto de revalorização da ZOPACAS e de inserção da temática marítima na CPLP, fazem parte de um esforço de construção de um "cinturão de boa vontade" que permite o avanço dos interesses brasileiros, mesmo além da área de segurança e defesa. Nesse sentido, nota-se uma ligeira mudança na retórica brasileira. Durante o governo Lula, o então ministro da Defesa, Nelson Jobim, caracterizava qualquer aumento da Organização do Tratado do Atlântico Norte (OTAN) no Atlântico Sul como "inapropriada" e afirmava a região como uma área distinta do Atlântico Norte - rejeitando, até mesmo, uma agenda comum ${ }^{15}$. Jobim também criticou como "carta branca" o novo conceito estratégico da OTAN, que determina que a aliança tem condição de intervir em qualquer lugar do mundo onde os interesses dos países integrantes tenham sido lesados ${ }^{16}$. É importante notar que esse discurso coexiste com iniciativas concretas de cooperação com países individuais da OTAN.

14 Disponível em <https://www.mar.mil.br/secirm/p-proarea.html>, acesso em maio de 2013.

$15 \mathrm{O}$ ministro Jobim afirmou que o discurso constituía visão de caráter pessoal a respeito do tema, não constituindo posiçăo oficial do governo brasileiro. Disponível em <https://www.defesa.gov.br/arquivos/File/2010/ mes09/o_futuro_da_comunidade.pdf>, acesso em maio de 2013.

16 Disponível em <http://oglobo.globo.com/politica/otan-ganhou-carta-branca-para-intervir-em-qualquerlugar-diz-jobim-2799889>, acesso em maio de 2013. 
Por exemplo, pouco tempo após reiterar o seu apoio à posição argentina em relação às Malvinas/Falklands, o Brasil assinou o acordo de cooperação em defesa com a Grã-Bretanha. E, apesar de um forte discurso soberanista que ressalta preocupações com possíveis ações unilaterais por parte dos EUA, inclusive a renovação do SOUTHCOM e da Quarta Frota da Marinha americana, o Brasil mantém fortes laços de cooperação com os EUA, dentro e fora da área da defesa.

Mais recentemente, o discurso brasileiro se amplia em referência a "atores externos à região", refletindo a inclusão de potências emergentes de fora da região dentre os possíveis contestadores da abordagem brasileira. Tal inclusão seria explicada pelo rápido aumento de interesses e presenças no Atlântico Sul de atores de fora. A China, por exemplo, tem relações de cooperação com todos os países dos dois lados do Atlântico Sul, salvo aqueles que ainda mantêm relaçôes diplomáticas com Taipei (Abdenur e Marcondes Neto 2013). Há, por fim, a vinculação crescente do Atlântico Sul com a Antártida, em vista dos recursos naturais presentes no continente e que também são cada vez mais alvo de interesse das potências emergentes.

\section{A ecologia de atores no Atlântico Sul}

Conforme apresentamos anteriormente, o processo de construção da região liderado pelo Brasil não acontece em um vácuo de poder, e sim em um contexto de crescente dinamismo por parte de atores de dentro e de fora da região. Alguma contestação a respeito da narrativa brasileira já existia quando da criação da ZOPACAS. Na época, a ZOPACAS recebeu apoio de 124 Estados-membros da ONU, mas países europeus como Alemanha, Bélgica, França, Itália, Holanda, Portugal e Luxemburgo, e também o Japão, decidiram pela abstenção, sendo os Estados Unidos o único Estado-membro a ter votado contra a resolução. Tanto os países europeus citados quanto os EUA e o Japão temiam que a resolução pudesse dificultar a liberdade de navegação no Atlântico Sul (Rosa 2006).

Tais questionamentos também envolvem a forma como o Atlântico Sul é identificado por alguns atores externos e internos. Para o então segundo comandante do Comando Aliado Conjunto da OTAN, o almirante português Fernando Melo Gomes, o Atlântico Sul era caracterizado por uma "desordem estratégica" e pela ausência de uma "arquitectura regional de segurança efectiva" (Gomes 2006, 236). Em 2010, o Brasil expressou preocupação quanto à possibilidade de um maior interesse da OTAN no contexto do Atlântico Sul, principalmente após a divulgação do NATO 2020 Assured Security Dynamic Engagement, documento que menciona a possibilidade de cooperação com países não pertencentes ao limite geográfico da atuação da aliança. Tal possibilidade já havia se realizado, por exemplo, no exercício final de consolidação da Força de Resposta Rápida da OTAN em Cabo Verde, em 2006 (Gomes 2006). Além de haver ressaltado a diferença nas questôes de segurança nos contextos dos Atlânticos Norte e Sul, 
o ministro Jobim afirmou em seu discurso na XII Reunião de Ministros da Defesa da CPLP preocupação com a Iniciativa para o Atlântico Sul, proposta por Portugal e Espanha, que visava à cooperação política entre os países da Europa, África e América do Sul (Ministério da Defesa 2010; CPLP 2010).

As relaçôes do Brasil com os países sul-atlânticos vizinhos também merece destaque. Em janeiro de 2011, Brasil e Argentina assinaram acordo entre as comissóes nucleares nacionais ${ }^{17}$ para avançar o desenvolvimento do combustível nuclear, mas que também serve para modular a rivalidade (histórica e potencial) entre os dois países (Herz 2010). A Argentina, afinal, também se interessa cada vez mais pelo Atlântico Sul e pela Antártida, mesmo além das Malvinas/Falklands, e vem lançando suas próprias iniciativas de cooperação em defesa com países africanos, em especial África do Sul, Nigéria e Angola ${ }^{1819}$. Para a Argentina, os encontros da Cúpula América do Sul-África fornecem uma oportunidade para apoio político e diplomático por parte dos países africanos em relação às reivindicaçōes argentinas a respeito das Malvinas/Falklands ${ }^{20}$.

Apesar do maior interesse por parte da Argentina, o Brasil permanece de longe o maior país no perímetro do Atlântico Sul - em termos de território, população, economia e poder/capacidade de defesa. Além disso, a expansão do poder militar brasileiro tem superado de longe os investimentos feitos pelos vizinhos sul-americanos, em especial aqueles localizados no Atlântico Sul. Ao promover essa identidade regional, o Brasil também amplia a sua capacidade de avançar interesses econômicos, políticos e estratégicos, mas ao mesmo tempo tal esforço demanda um papel cada vez mais ativo do País em relação a questões de segurança no Atlântico Sul, especialmente na África.

Nessa empreitada, o Brasil tem a vantagem de não ter disputas com os demais países da região. Mesmo a rivalidade com a Argentina, que chegou a incluir um componente de corrida armamentista, foi dissipada na década de 1990. No entanto, a abordagem brasileira pode produzir ou exacerbar certas tensões. $\mathrm{O}$ antagonismo entre a Argentina e o Reino Unido ressurge com a descoberta de reservas de petróleo offshore perto das Malvinas/Falklands. As reinvindicaçôes desses dois países junto à Convenção da ONU sobre Direito do Mar se sobrepõem - um elemento de tensão ainda não resolvido (Dodds 2012a, 2012b). Certos países da costa da África também têm fronteiras marítimas mal resolvidas, como no caso de São Tomé e Príncipe. Finalmente, há certos focos de instabilidade na região, tais como no Golfo da Guiné e no Mali.

17 Disponível em <http://www.abacc.org.br/wp-content/uploads/2011/08/Declara\%C3\%A7\%C3\%A3o_BsAs_ PT.pdf>, acesso em maio de 2013.

18 Disponível em <http://www.esafr.mrecic.gov.ar/userfiles/MOUCooperaci\%C3\%B3ndefensaEsp.pdf>, acesso em maio de 2013.

19 Disponível em <http://www.prensa.argentina.ar/2012/07/27/32707-argentina-y-nigeria-compartieron-susvisiones-sobre-la-defensa.php>, acesso em maio de 2013.

20 Disponível em <http://www.itamaraty.gov.br/sala-de-imprensa/notas-a-imprensa/iii-cupula-de-chefes-deestado-e-de-governo-america-do-sul-africa-asa-declaracao-de-malabo>, acesso em maio de 2013. 
Frente a esse cenário, a cooperação com os EUA no Atlântico Sul também pode ser interpretada como uma tentativa de encontrar temas de segurança e defesa de interesse comum, tal como o combate à pirataria no Golfo das Guiné. Oficiais da Marinha brasileira vêm participando, na condição de observadores, de exercícios de combate à pirataria liderados pelos EUA e contando com a presença de países europeus, em 2012 e em 2013, na costa atlântica da África (Marinha do Brasil 2012; AFRICOM 2013). Além da troca de experiências, para o Brasil a cooperação com os EUA serve para moderar a contestação americana decorrente não apenas da projeção brasileira na América do Sul e na África, mas também pela concorrência da indústria de defesa brasileira em alguns mercados.

\section{Conclusão}

O Brasil vem se mostrando como region-builder em diversos aspectos. $\mathrm{Na}$ sua estratégia para o Atlântico Sul, os esforços brasileiros no âmbito doméstico estão fortemente vinculados aos programas de cooperação em defesa, tanto no âmbito bilateral quanto na sua dimensão multilateral. Ambos visam a fortalecer a identidade marítima dos países do perímetro do Atlântico Sul, sublinhando não apenas as preocupações em comum, mas também a percepção de que há uma necessidade de proteger os recursos oceânicos de ambos os lados do Atlântico Sul, especialmente o pré-sal. O Brasil, ao ativamente disseminar a centralidade dos recursos marinhos na sua estratégia de defesa e nos seus esforços de cooperação naval, se esforça para construir uma identidade regional sul-atlântica. Tais esforços se encaixam nos tipos de comportamento identificados pela literatura sobre a construção de regiōes e observadas em outras partes do mundo.

Tal identidade está longe de ser simétrica ou isenta de possíveis contestações. Ao assumir um protagonismo no processo de construção da identidade sul-atlântica, mesmo adotando um discurso de horizontalidade e enfatizando as inciativas multilaterais, o Brasil procura aumentar sua capacidade de avançar seus próprios interesses econômicos e políticos nesse espaço. Sendo já o maior país da região (em termos econômicos e de capacidade militar), o aumento do poder naval, ainda que para efeitos dissuasórios, pode alimentar a percepção de assimetrias na região - levando a uma contestação da estratégia brasileira, tanto por países do Atlântico Sul assim como por aqueles de fora. Para modular essas possíveis reaçôes, o Brasil adota um posicionamento que combina distanciamento e cooperação - às vezes, em relação ao mesmo parceiro. Apesar de o Brasil ter superado sua rivalidade com a Argentina, o aumento da capacidade militar brasileira não passa despercebido em Buenos Aires. Ao mesmo tempo em que o Brasil reitera seu apoio à posição argentina em relação às Malvinas/Falklands e avança na implementação de um acordo de cooperação na área de energia nuclear, ele amplia sua cooperação em defesa com a Reino Unido. Com os EUA, a cooperação e o distanciamento presentes na estratégia brasileira são ainda mais aparentes, envolvendo tanto uma 
rejeição a uma presença ampliada dos EUA e da OTAN no Atlântico Sul quanto uma colaboração frente a ameaças comuns.

$\mathrm{Na}$ construção de uma identidade sul-atlântica que beneficie o Brasil, a estratégia brasileira poderia ainda vir a exacerbar certas tensões (diretamente ou não relacionadas ao Brasil). Por exemplo, a cooperação no levantamento das plataformas continentais e a formulação de propostas de expansão legal das águas jurisdicionais podem estimular na região um novo territorialismo marítimo. Considerando a existência de focos de tensão entre certos atores no Atlântico Sul, as iniciativas em curso fomentam uma maior disposição competitiva em relação aos recursos e espaço marítimos. Portanto, ao avançar sua estratégia de consolidação de uma identidade sul-atlântica, o governo brasileiro deve levar em conta a multiplicidade de interesses no Atlântico Sul, assim como a possibilidade de outros atores construírem narrativas concorrentes.

\section{Referências bibliográficas}

ABDENUR, Adriana; MARCONDES NETO, Danilo (2013) "China en el Atlántico Sur”. Revista CIDOB d'Afers Internacionals 102-103. Redescubrir el espacio atlântico.

ACHARYA, Amitav (2011). The making of Southeast Asia: the international relations of a region. Oxford: Oxford University Press.

ADLER, Emmanuel; BARNETT, Michael, Eds. (1998) Security communities, Cambridge: Cambridge University Press.

AFRICOM (2013) Obangame Express 2013 Comes to a Successful Close. Março, 2013. Disponível em: <http://www.africom.mil/Newsroom/Article/10389/exercise-obangameexpress-2013>. Acesso em: maio de 2013.

ANDERSON, Benedict (1983) Imagined Communities: reflections on the origin and spread of Nationalism. London.

BELLAMY, Alex (2004) Security Communities and their neighbours: regional fortresses or global integrators? London: Palgrave Macmillan.

BENWELL, Matthew C.; DODDS, Klaus (2011) Argentine territorial nationalism revisited: The Malvinas/Falklands dispute and geographies of everyday nationalism. Political Geography, Vol. 30, No. 6, p. 1-19.

CARVALHO, Roberto de Guimarães (2013) A outra Amazônia. Folha de São Paulo, 25 de fevereiro de 2004. Disponível em: <http://www1.folha.uol.com.br/fsp/opiniao/fz2502200409. htm> Acesso em: maio 2013

CPLP (2010) Declaração Final da XII Reunião de Ministros da Defesa Nacional da Comunidade dos Países de Língua Portuguesa. Brasília.

DÁVILA, Jerry (2010) Hotel Trópico. Brazil and the challenge of African decolonization, 1950-1980. Durham: Duke University Press.

DODDS, Klaus (2012a) Stormy waters: Britain, the Falkland Island and UK-Argentine relations. International Affairs, Vol. 88, No. 4, p. 683-700.

(2012b) The Falkland Islands as strategic gateway: Britain and the South Atlantic Overseas Territories RUSI Journal, Vol. 157, No. 6, p. 18-25. 
(2011) Sovereignty watch: claimant states, resources, and territory in contemporary Antarctica. Polar Record, Vol. 47, No. 242, p. 231-245.

DODDS, Klaus \& INGIMUNDARSON, Valur (2012) Territorial nationalism and Arctic geopolitics: Iceland as an Arctic coastal state. The Polar Journal, Vol. 2, No. 1, p. 21-37.

GOMES, Fernando Melo. O valor estratégico do Atlântico Sul (2006) In Manuela Franco (coord) Portugal, os Estados Unidos e a África Austral. III Conferência Internacional, FLAD-IPRI, 10 a 11 de novembro de 2005. Fundação Luso-Americana, Lisboa, p. 235-243.

HERZ, Monica (2010) Segurança Internacional na América do Sul. In: Nelson A. Jobim; Sergio W. Etchegoyen e João Paulo Alsina. (Org.). Segurança Internacional: Perspectivas Brasileiras. Rio de Janeiro: Getúlio Vargas, p. 331-344.

HURRELL, Andrew (1983) The politics of South Atlantic security: a survey of proposals for a South Atlantic Treaty Organization. International Affairs, Vol. 59, No. 2, p. 179-193.

IBGE (2011) IBGE em parceria com a Marinha do Brasil lança o Atlas Geográfico das Zonas Costeiras e Oceânicas. Disponível em: <http://saladeimprensa.ibge.gov.br/noticias?view=noti cia\&id=1\&busca=1\&idnoticia=2036>. Acesso em: maio de 2013.

KESKITALO, E. C. H. (2004) Negotiating the Arctic. The construction of an international region. New York: Routledge.

LEANDRO, Roberto Pacheco (2011) Comunidade dos Países de Língua Portuguesa: espaço estratégico para afirmação do prestígio militar brasileiro. Trabalho de Conclusão de Curso apresentado ao Departamento de Estudos da Escola Superior de Guerra como requisito à obtenção do diploma do Curso de Altos Estudos de Política e Estratégia. ESG.

MARINHA DO BRASIL (s. d.) Relatório da I Reunião dos Ministros de Assuntos do Mar da CPLP. Secretaria da Comissão Interministerial para os Recursos do Mar (SECIRM).

MARINHA DO BRASIL (2013) Marinha do Brasil participa do exercício Obangame Express na Nigéria, 2012. Disponível em: <http://www.mar.mil.br/nomaronline/noticias/16032012/08. html>. Acesso em: maio de 2013.

MARTINS FILHO, João Roberto (2007) The Brazilian Armed Forces in the Post-Cold War Era: What Has Changed in Military Thinking? Centre for Brazilian Studies, University of Oxford, Working Paper No. 85.

MEDEIROS, Roberto Carvalho de (2002) O Acordo de Cooperação Militar Brasil-Namíbia como instrumento de consolidação da Zona de Paz e Cooperação do Atlântico Sul. Revista Marítima Brasileira Vol. 122, No. 7/9, p. 167-190.

MINISTÉRIO DA DEFESA (2013) Communique on the occasion of the official visit of H. E. Celso Amorim, Minister of Defence of the Federative Republic of Brazil, February 2013. Disponível em: <https://www.defesa.gov.br/arquivos/2013/pronunciamentos/comunicados_ conjuntos/communique_on_the_occasion_of_the_offcial_visit_minister_of_defence_brazil. pdf> Acesso em: maio 2013.

MINISTÉRIO DA DEFESA (2010) Palestra do Ministro da Defesa do Brasil, Nelson Jobim no Encerramento da Conferência Internacional: o futuro da comunidade transatlântica. Instituto de Defesa Nacional, Lisboa.

MIYAMOTO, Shiguenoli (1987) Atlântico Sul: zona de paz e de cooperação? Lua Nova Vol.3, No.3, p. 21-23.

NEUMANN, Iver B. (1999) Uses of the other. The East in European identity formation. Minneapolis: University of Minnesota Press. 
(1994) A region-building approach to Northern Europe. Review of International Studies, Vol. 20, No. 1, p. 53-74.

PENNA FILHO, Pio (2003) Regionalismo, segurança e cooperação: O Atlântico Sul como espaço de possibilidades entre o Cone Sul e a África Austral” Trabalho apresentado no XXVII Encontro Nacional da ANPOCS, 21 a 25 de outubro de Caxambu, MG.

ROSA, Manuel Amante da (2006) O Atlântico Sul perante os novos desafios mundiais” In In: FRANCO, Manuela (coord). Portugal, os Estados Unidos e a África Austral. III Conferência Internacional, FLAD-IPRI, 10 a 11 de novembro de 2005. Lisboa: Fundação Luso-Americana, Lisboa, p. 249-265.

SARAIVA, José Flávio Sombra (1996) O lugar da África: A dimensão atlântica da política externa brasileira. Brasília: UnB.

SECIRM (2010) Relatório da I Reunião dos Ministros dos Assuntos do Mar da CPLP. Secretaria da Comissão Interministerial para os Recursos do Mar, Marinha do Brasil.

SIPRI (2012) Stockholm International Peace Research Institute Yearbook 2012. Armaments, disarmament and international security. Oxford: Oxford University Press.

(2011). Stockholm International Peace Research Institute Yearbook 2011. Armaments, disarmament and international security. Oxford: Oxford University Press.

SIPRI (2009) Stockholm International Peace Research Institute Yearbook 2009. Armaments, disarmament and international security. Oxford: Oxford University Press.

VAN LANGENHOVE, Luk (2011) Building regions. The regionalization of the world order. Aldershot: Ashgate.

Recebido em 27 de setembro de 2013

Aprovado em 31 de outubro de 2013

\section{Resumo}

O artigo analisa a cooperação que o Brasil vem desenvolvendo ao longo do Atlântico Sul, mostrando que o País vem desempenhando o papel de region-builder na construção de uma identidade sul-atlântica com posição de destaque para si. Tais esforços começam a ser contestados por outros atores de dentro e fora da região.

Palavras-chave: Atlântico Sul; Brasil; Cooperação; Defesa; ZOPACAS.

\section{Abstract}

This article analyzes the cooperation that Brazil has been developing across the South Atlantic, showing that Brazil has adopted the role of region-builder, working to construct a South Atlantic identity while it secures for itself a position of preeminence. Such efforts begin to be contested by other actors from within and outside the region.

Keywords: South Atlantic; Brazil; Cooperation; Defense; ZOPACAS. 